\title{
Assessment of wind energy potential at Kuwaiti Islands by statistical analysis of wind speed data
}

\author{
Khaled Al-Salem ${ }^{1^{*}}$, Waleed Al-Nassar ${ }^{1}$ \\ ${ }^{1}$ Kuwait Institute for Scientific Research
}

\begin{abstract}
Kuwait possesses a potential of renewable energy, such as solar and wind energy. Wind energy is an alternative clean energy source compared to fossil fuel, which pollute the lower layer of the atmosphere. In this study, statistical methods are used to analyze the wind speed data at Mubarak port (at Bubiyan Island), Failaka Island and Um-AlMaradim Island; which are located respectively in the north, mid and south of Kuwait territorial waters. Wind speed is the most important parameter in the design and study of wind energy conversion systems. The wind speed data were obtained from the Costal Information System Database (CIS) at Kuwait Institute for Scientific Research [1, 2 and 3]over a thirty seven years period, 1979 to 2015. In the present study, the wind energy potential of the locations was statistically analyzed based on wind speed data, over a period of thirty seven years. The probability distributions are derived from the wind data and their distributional parameters are identified. Two probability density functions are fitted to the probability distributions on a yearly basis. The wind energy potential of the locations was studied based on the Weibull and the Rayleigh models.
\end{abstract}

\section{Introduction}

Increasing negative effects of fossil fuel combustion on the environment in addition to its limited stock have forced many countries to explore and change to environmentally friendly alternatives that are renewable to sustain the increasing energy demand. Changing to renewable sources and the implementation of effective conservation measures would ensure sustainability. Alternatives to conventional energy sources, especially the renewable ones, are becoming increasingly attractive because of the limited fossil fuel reserves and the adverse effects associated with their use. Some of renewable energy resources are solar and wind. All these renewable energy resources are abundant in Kuwait [4 and 5]. If these resources are well harnessed, they can provide complete security of energy supply. Currently, the wind energy is one of the fastest developing renewable energy source technologies across the globe. Wind energy is an alternative clean energy source compared to fossil fuel, which pollute the lower layer of the atmosphere. It has the advantage of being suitable to be used locally in rural and remote areas. The increasing demand for energy supply coupled with limited energy resources creates an urgency to find new solutions for this energy shortage. Nowadays, wind analysis gives remarkable information to researchers involved in renewable energy studies. Knowledge of the statistical properties of the wind speed is essential for predicting the energy output of a wind energy conversion system. Because of the high variability in space and time of wind energy, it is important to verify that the analyzing method used for the wind data will yield the estimated energy of the wind speed distribution. One of the wind characteristics, is of great importance not only for structural and environmental design and analysis, but also for the assessment of the wind energy potential and the performance of wind energy conversion system as well. Over the last two decades many researches have been devoted to develop an adequate statistical model to describe wind speed frequency distribution. The Weibull, Rayleigh and Lognormal functions are commonly used for fitting the measured wind speed probability distribution [6]. The aim of the present work is to evaluate the potentiality of wind energy at the following locations shown in figure 1:

- Mubarak Port located in Bubiyan island; which is one of the largest island in Kuwait waters and located in the North of Kuwait $\left(29^{\circ} 50^{\prime}\right.$ $\left.31.3^{\prime \prime} \mathrm{N}, 48^{\circ} 17^{\prime} 35.3^{\prime \prime} \mathrm{E}\right)$.

- Failaka island located in the middle of the terrestrial waters of Kuwait $\left(29^{\circ} 26^{\prime} 08.0^{\prime \prime} \mathrm{N} 48^{\circ}\right.$ 16' 41.3"EE).

- Umm-AlMaradim island located in the south of terrestrial waters of Kuwait ( $28^{\circ} 40^{\prime} 44.7^{\prime \prime} \mathrm{N}$ $48^{\circ} 39^{\prime} 05.1$ "E ).

*Corresponding author: ksalem@kisr.edu.kw 


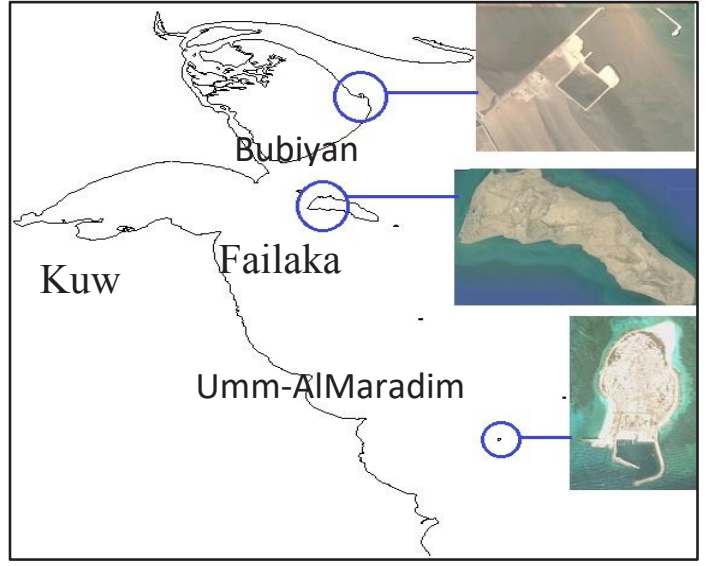

Figure 1. Location of Kuwaiti Islands in Arabian Gulf.

\section{Methodology and Analysis}

Frequency distribution of wind speed: The wind speed probability density distributions and their functional forms represent the major aspects in wind related literature. Their use includes a wide range of applications, including identifying the parameters of the distribution functions and analyzing the wind speed data as well as wind energy. The wind speed distribution can be determined by dividing the wind speed domain into a number of intervals, mostly of equal width of $1 \mathrm{~m} / \mathrm{s}$. The suitable statistical analysis, of the wind speed data in time series format were transformed into frequency distribution format. Based on the wind speed classes, the frequency distribution of the wind speed was established and shown by the Table 1 . The wind speed frequency of occurrence of each speed class $f\left(v_{i}\right)$ can found by the following:

$f\left(v_{i}\right)=\frac{f_{i}}{N}$

Where, vi the mean wind speeds calculated for each speed class intervals.

$f i$ the frequency of occurrence of each speed class

$N$ the total data occurrence of each class (12 number of month in a year).

Two of the commonly used functions for fitting a measured wind speed probability distribution in a given location over a certain period of time are the Weibull and Rayleigh distributions [7 and 8]. The probability density function of the Weibull distribution is given as follows:

$f(v)=\left(\frac{k}{c}\right)\left(\frac{v}{c}\right)^{k-1} \exp \left[-\left(\frac{v}{c}\right)^{k}\right]$

Here, $f(v)$ is the probability of observing wind speed $v$; $\mathrm{c}$ is the Weibull scaling parameter and $\mathrm{k}$ is the dimensionless Weibull shape parameter. The corresponding cumulative probability function of the Weibull distribution is given by:

$F(v)=1-\exp \left[-\left(\frac{v}{c}\right)^{k}\right]$

The Rayleigh distribution is a special case of the Weibull distribution in which the shape parameter $\mathrm{k}$ takes the value 2.0. From equation 1 the probability density function for the Rayleigh distribution can be simplified as following:

$f(v)=\left(\frac{2 v}{c^{2}}\right) \exp \left[-\left(\frac{v}{c}\right)^{k}\right]$
The mean value $v_{m}$ and standard deviation $\sigma$ of the Weibull distribution [9] can be computed as:

$v_{m}=\mathrm{c} \neg\left[1+\frac{1}{k}\right]$

Where standard deviation $\sigma$

$\sigma=\mathrm{c}\left[\neg\left(1+\frac{2}{k}\right)-\neg^{2}\left(1+\frac{1}{k}\right)\right]^{\frac{1}{2}}$

Where $\neg$ is the gamma function.

Wind speed variation with height: Wind speed near the ground changes with height. This requires an equation that predicts the wind speed at one height in terms of the measured speed at another. The most common expression for the variation of wind speed with height is the power law [10] having the following form:

$\frac{v_{2}}{v_{1}}=\left[\frac{h_{2}}{h_{1}}\right]^{\propto}$

Where $v_{1}$ and $v_{2}$ are the mean wind speeds at heights $h_{1}$ and $h_{2}$, respectively. The exponent $\propto$ depends on factors such as surface roughness and atmospheric stability definitions according to the [European Wind Atlas, WASP]. Numerically, it lies in the range $0.0-0.5$, with the most frequently adopted value being 0.5 which is applicable to low surfaces and well exposed will used a roughness length 0.0024 .

Where equation 6 can be written as follows:

$\frac{v_{2}}{v_{1}}=\frac{\ln \left(\frac{h 2}{r}\right)}{\ln \left(\frac{h 1}{r}\right)}$

Where $\mathrm{r}$ is Roughness Length $(\mathrm{m}), v_{2}$ wind speeds at selected ground level $h_{2}$.

The wind speed at a certain height above ground level is

$v_{2}=v_{1}\left[\frac{\ln \left(\frac{h 2}{r}\right)}{\ln \left(\frac{h 1}{r}\right)}\right]$

The fact that the wind profile is twisted towards a lower speed as we move closer to ground level is usually called wind shear. Wind shear may also be important when designing wind turbines.

Wind Power density function: It is well known that the power of the wind at speed $v$ through a wind turbines blade sweep area $(A)$ increases as the cube of its velocity and can be calculated as follows [2 and 11]: $P(v)=\frac{1}{2} \rho A v^{3}$

Where $\rho$ is the mean air density $\left(1.225 \frac{\mathrm{kg}}{\mathrm{m}^{3}}\right.$ at average atmospheric pressure at sea level and at $15^{\circ} \mathrm{C}$ ). The expected monthly or annual wind power density per unit area of a site based on a Weibull probability density function can be expressed as follows:

$P_{w}=\frac{1}{2} \rho c^{3} \neg\left[1+\frac{3}{k}\right]$

To calculate Weibull shape parameter or factor $(K)$ is by iteration method by using maximum likelihood method as the following:

$k=\left(\frac{\sum_{1}^{n} v^{k} \operatorname{Ln}(v)}{\sum_{1}^{n} v^{k}}-\frac{\sum_{1}^{n} \operatorname{Ln}(v)}{n}\right)^{-1}$

Where $c$ is the Weibull scale parameter $(\mathrm{m} / \mathrm{s})$, and is given by:

$c=\frac{v_{m}}{\neg\left(1+\frac{1}{k}\right)}$

Then, Weibull scale parameter is calculated as follows 


$$
c=\left(\frac{\sum_{1}^{n} v^{k}}{n}\right)^{\frac{1}{k}}
$$

The two significant parameters $k$ and $C$ are closely related to the mean value of the wind speed $v_{m}$ [12]. By extracting $C$ from Equation [12] and $K$, the power density for the Rayleigh model can be found by [13]:

$P_{R}=\frac{3}{\pi} \rho c^{3}\left(\frac{\pi}{4}\right)^{\frac{3}{2}}$

Errors in calculating the power densities using the distributions in comparison to values of the probability density distributions derived from measured values can be found by the following:

$\operatorname{Error}(\%)=\frac{\left(P_{W, R}-P_{m, R}\right)}{P_{m, R}}$

where $P_{W, R}$ is the mean power density calculated from either the Weibull or Rayleigh function used in the calculation of the error and $P_{m, R}$ is the wind power density for the probability density distribution, derived from measured values which serves as 'the reference mean power density'. And can be calculated from the following [13]:

$P_{m, R}=\sum_{j=1}^{n}\left[\frac{1}{2} \rho v_{m}^{3} f\left(v_{j}\right)\right]$

The yearly average error value in calculating the power density using the Weibull function is given by the following:

$\operatorname{Error}(\%)=\frac{1}{12} \sum_{i=1}^{12}\left[\frac{\left(P_{W, r}-P_{m, R}\right)}{P_{m, R}}\right]$

The statistical analysis of the distributions: The square of the correlation coefficient $\left(R^{2}\right)$, chi-square $\left(X^{2}\right)$ and root mean square error analysis (RMSE) are used to evaluate the performances of the Weibull and Rayleigh distributions [6]. These parameters can be calculated as follows:

$R^{2}=\frac{\left(\sum_{i=1}^{N}\left(y_{i}-Z_{i}\right)^{2}-\sum_{i=1}^{N}\left(x_{i}-y_{i}\right)^{2}\right)}{\sum_{i=1}^{N}\left(y_{i}-Z_{i}\right)^{2}}$

$x^{2}=\frac{\sum_{i=1}^{n}\left(y_{i}-x_{i}\right)^{2}}{N-n}$

$R M S E=\left[\frac{1}{N} \sum_{i=1}^{N}\left(y_{i}-x_{i}\right)^{2}\right]^{\frac{1}{2}}$

Where $y_{i}$ is the measured data, $Z_{i}$ is the mean value, $x_{i}$ is the predicted data with the Weibull or Rayleigh distribution, $N$ is the number of observations and $n$ is the number of constants. Therefore, the distribution function can be selected according to the highest value of $R^{2}$ and the lowest values of RMSE and $x^{2}$.

\section{Discussion and Results}

Data for wind speed used in the present calculations were obtained during the period 1979-2015 from the Coastal Information system Database at KISR[1, 2 and $3]$. The wind data used were numerically predicted and validated with Kuwait Airport data[2 and 14] and the three locations in the study were positioned in open spaces free of obstacles at a height of $30 \mathrm{~m}$ above the ground. Wind speeds stored and averaged over one hour in the database. The main results obtained from the present study can be summarized as follows.

The Monthly mean wind speed values at $30 \mathrm{~m}$ height and the standard deviations calculated from the available data for period of 37 years (1979-2015) as shown in Table 1 for the three selected location presented as follows:

- For Mubarak port at Bubiyan Island indicated for the overall 37 years, the mean wind speeds is about $4.5 \mathrm{~m} / \mathrm{s}$. The wind speed for the whole year has the maximum monthly mean value of $5.4 \mathrm{~m} / \mathrm{s}$ which arises in June, while a minimum value of $3.9 \mathrm{~m} / \mathrm{s}$ occurs in October.

- Similarly, for Failaka Island, the mean wind speeds is about $4.46 \mathrm{~m} / \mathrm{s}$. The wind speed for the whole year has the maximum monthly mean value of $5.24 \mathrm{~m} / \mathrm{s}$ which arises in June, while a minimum value of $3.77 \mathrm{~m} / \mathrm{s}$ occurs in October.

- Similarly, for Umm AlMaradim Island, the mean wind speeds is about $4.66 \mathrm{~m} / \mathrm{s}$. The wind speed for the whole year has the maximum monthly mean value of $5.44 \mathrm{~m} / \mathrm{s}$ which arises in June, while a minimum value of $3.97 \mathrm{~m} / \mathrm{s}$ occurs in October.

To construct the wind speed probability distributions we need to determine frequency distribution of the wind speed, we must first divide the wind speed domain into a number of intervals, mostly of equal width of $1 \mathrm{~m} / \mathrm{s}$. As a result, for a suitable statistical analysis, the wind speed data in time series format were transformed into monthly frequency distribution format. Based on the wind speed bins, the frequency distribution of the wind speed data was established for the three selected location and shown by Tables 2,3 and 4. As the tables indicates, the trends of the monthly means for the different years are similar for all selected locations.

The variation of wind velocity is often described using the Weibull two-parameter density function. This is a statistical method which is widely accepted for evaluating local wind load probabilities and considered as a standard approach. The Weibull shape function $k$ and scale factor $c$ parameters are calculated analytically from the available data are presented as a mean values in Table 5 for Bubiyan Island, Failaka Island and for Umm AlMaradim. As shown, the scale parameter $c$ for the selected locations varies over the whole period (1979-2015) show the following:

- Bubiyan Island 1.63 (November 2009) and $6.45 \mathrm{~m} / \mathrm{s}$ (August 1994).

- Failaka Island 1.9 (October 2008 and December 2009) and $6.7 \mathrm{~m} / \mathrm{s}$ (June 2005).

- Umm AlMaradim Island 1.38 (December 2009) and $6.47 \mathrm{~m} / \mathrm{s}$ (July 1994).

Where shape parameter $K$ ranges as follows:

- Bubiyan Island 1.42 (November 2009) and 4.21 (July 1994).

- $\quad$ Failaka Island 1.45 (February 2009) and 4.13 (August 1997).

- Umm AlMaradim Island 1.34 (January 2009) and 4.07 (July 1991). 
Table 1. Monthly mean wind speeds $(\mathrm{m} / \mathrm{s})$ and standard deviations $(\sigma)$ at Bubiyan, Failaka and Umm AlMaradim Islands in Kuwait waters, for periods of 1979-2015

\begin{tabular}{|c|c|c|c|c|c|c|c|c|c|c|c|c|c|c|}
\hline Locations & & Jan & Feb & Mar & Apr & May & Jun & Jul & Aug & Sep & Oct & Nov & Dec & Year \\
\hline \multirow{3}{*}{$\begin{array}{l}\text { Bubiyan } \\
\text { Island }\end{array}$} & $\mathrm{M}$ & 4.46 & 4.81 & 4.77 & 4.67 & 4.67 & 5.39 & 5.21 & 4.62 & 4.08 & 3.90 & 4.25 & 4.34 & 4.60 \\
\hline & W.S & & & & & & & & & & & & & \\
\hline & $\sigma$ & 1.99 & 2.13 & 2.15 & 2.04 & 1.98 & 2.31 & 2.11 & 1.91 & 1.79 & 1.70 & 1.82 & 1.90 & 1.99 \\
\hline \multirow{3}{*}{$\begin{array}{l}\text { Failaka } \\
\text { Island }\end{array}$} & M & 4.29 & 4.64 & 4.63 & 4.47 & 4.45 & 5.24 & 5.16 & 4.58 & 4.01 & 3.77 & 4.11 & 4.22 & 4.46 \\
\hline & W.S & & & & & & & & & & & & & \\
\hline & $\sigma$ & 1.89 & 2.02 & 2.06 & 1.98 & 1.93 & 2.24 & 2.08 & 1.89 & 1.78 & 1.63 & 1.74 & 1.82 & 1.92 \\
\hline \multirow{3}{*}{$\begin{array}{l}\text { Umm } \\
\text { AlMaradim }\end{array}$} & M & 5.54 & 5.81 & 5.68 & 5.50 & 5.50 & 6.47 & 6.21 & 5.51 & 4.90 & 4.70 & 5.27 & 5.43 & 5.54 \\
\hline & W.S & 04 & 253 & 256 & 230 & 234 & 770 & 257 & 233 & 218 & 205 & 225 & 234 & 20 \\
\hline & $\sigma$ & 2.40 & 2.03 & 2.56 & 2.39 & 2.34 & 2.19 & 2.57 & 2.33 & 2.18 & 2.05 & 2.25 & 2.34 & 2.39 \\
\hline
\end{tabular}

Table 2. Wind speed data transformed into monthly frequency distribution format for Mubarak Port at Bubiyan Island at 30m height for periods 1979-2015.

\begin{tabular}{llllllllllll}
\hline & & & \multicolumn{1}{c}{ Wind Speed bins (m/s) } \\
No/Sp & $0 .-1.0$ & $1 .-2.0$ & $2 .-3.0$ & $3 .-4.0$ & $4 .-5.0$ & $5 .-6.0$ & $6 .-7.0$ & $7 .-8.0$ & $8 .-9.0$ & $9 .-10$. & $>10$ \\
\hline Jan & 0.029 & 0.0863 & 0.1368 & 0.1961 & 0.1889 & 0.1484 & 0.0933 & 0.0616 & 0.0343 & 0.0145 & 0.0109 \\
Feb & 0.0166 & 0.0644 & 0.1222 & 0.199 & 0.1871 & 0.1449 & 0.1031 & 0.0743 & 0.0409 & 0.0257 & 0.0218 \\
Mar & 0.0203 & 0.067 & 0.1332 & 0.1902 & 0.1817 & 0.1411 & 0.1044 & 0.0719 & 0.0453 & 0.0223 & 0.0226 \\
Apr & 0.0203 & 0.0695 & 0.1331 & 0.1887 & 0.1914 & 0.151 & 0.1056 & 0.0655 & 0.0405 & 0.0206 & 0.0136 \\
May & 0.0186 & 0.0689 & 0.126 & 0.1949 & 0.1961 & 0.1543 & 0.103 & 0.0663 & 0.039 & 0.0191 & 0.0139 \\
Jun & 0.022 & 0.0609 & 0.0974 & 0.1369 & 0.1505 & 0.1449 & 0.1274 & 0.1023 & 0.0702 & 0.0445 & 0.0431 \\
Jul & 0.0243 & 0.0574 & 0.1015 & 0.1434 & 0.1713 & 0.1524 & 0.1218 & 0.0967 & 0.0638 & 0.0386 & 0.0289 \\
Aug & 0.0282 & 0.0776 & 0.1309 & 0.1796 & 0.1977 & 0.1391 & 0.1003 & 0.0695 & 0.0441 & 0.0196 & 0.0134 \\
Sep & 0.0304 & 0.1042 & 0.1668 & 0.2176 & 0.2117 & 0.1168 & 0.072 & 0.0428 & 0.0221 & 0.0098 & 0.006 \\
Oct & 0.0368 & 0.1095 & 0.1846 & 0.2435 & 0.1914 & 0.1043 & 0.0655 & 0.0336 & 0.0159 & 0.0068 & 0.0082 \\
Nov & 0.0338 & 0.0931 & 0.1473 & 0.2163 & 0.1867 & 0.1392 & 0.0938 & 0.0474 & 0.023 & 0.0114 & 0.008 \\
Dec & 0.0288 & 0.0925 & 0.1529 & 0.2077 & 0.1869 & 0.1333 & 0.0852 & 0.0556 & 0.0281 & 0.0169 & 0.0121 \\
Year & 0.0258 & 0.0793 & 0.1361 & 0.1928 & 0.1868 & 0.1391 & 0.0979 & 0.0656 & 0.0389 & 0.0208 & 0.0169 \\
Cumulative & 0.0258 & 0.105 & 0.2411 & 0.4339 & 0.6207 & 0.7598 & 0.8578 & 0.9234 & 0.9623 & 0.9831 & 1 \\
\hline
\end{tabular}

Table 3. Wind speed data transformed into monthly frequency distribution format for Failaka Island at 30m height for periods 1979 2015.

\begin{tabular}{lllllllllllll}
\hline & & & \multicolumn{1}{c}{ Wind Speed bins $(\mathrm{m} / \mathrm{s})$} \\
No/Sp & $0 .-1.0$ & $1 .-2.0$ & $2 .-3.0$ & $3 .-4.0$ & $4 .-5.0$ & $5 .-6.0$ & $6 .-7.0$ & $7 .-8.0$ & $8 .-9.0$ & $9 .-10$. & $>10$ \\
\hline Jan & 0.0295 & 0.0882 & 0.1453 & 0.2278 & 0.183 & 0.1395 & 0.0925 & 0.0488 & 0.025 & 0.0119 & 0.0086 \\
Feb & 0.0218 & 0.0638 & 0.1255 & 0.2181 & 0.1933 & 0.1455 & 0.0998 & 0.0594 & 0.0347 & 0.0221 & 0.0161 \\
Mar & 0.0234 & 0.0682 & 0.1281 & 0.2035 & 0.1866 & 0.1534 & 0.1073 & 0.0632 & 0.0317 & 0.0178 & 0.0168 \\
Apr & 0.0269 & 0.0774 & 0.1413 & 0.2044 & 0.1884 & 0.1481 & 0.0939 & 0.0588 & 0.0352 & 0.0148 & 0.0108 \\
May & 0.0209 & 0.0786 & 0.1458 & 0.2099 & 0.1988 & 0.1355 & 0.096 & 0.0604 & 0.0288 & 0.0156 & 0.0098 \\
Jun & 0.0188 & 0.0654 & 0.1052 & 0.1572 & 0.1555 & 0.1445 & 0.1171 & 0.09 & 0.0653 & 0.0404 & 0.0405 \\
Jul & 0.0181 & 0.0616 & 0.1045 & 0.1548 & 0.1725 & 0.1512 & 0.1205 & 0.0913 & 0.0624 & 0.0348 & 0.0283 \\
Aug & 0.0231 & 0.0767 & 0.1392 & 0.1968 & 0.19 & 0.1409 & 0.0911 & 0.0642 & 0.0453 & 0.0184 & 0.0143 \\
Sep & 0.0324 & 0.1033 & 0.1859 & 0.2322 & 0.1805 & 0.1142 & 0.0725 & 0.0385 & 0.0231 & 0.0116 & 0.0057 \\
Oct & 0.0378 & 0.1138 & 0.1952 & 0.2624 & 0.1829 & 0.1024 & 0.0511 & 0.0279 & 0.0139 & 0.0058 & 0.0068 \\
Nov & 0.0302 & 0.0981 & 0.1615 & 0.2418 & 0.1912 & 0.1185 & 0.0738 & 0.0468 & 0.0222 & 0.0083 & 0.0077 \\
Dec & 0.0353 & 0.0893 & 0.152 & 0.2318 & 0.1876 & 0.1277 & 0.0825 & 0.0463 & 0.0252 & 0.0128 & 0.0096 \\
Year & 0.0265 & 0.082 & 0.1441 & 0.2117 & 0.1842 & 0.1351 & 0.0915 & 0.058 & 0.0344 & 0.0178 & 0.0146 \\
Cumulative & 0.0265 & 0.1085 & 0.2527 & 0.4644 & 0.6486 & 0.7837 & 0.8752 & 0.9332 & 0.9676 & 0.9854 & 1 \\
\hline
\end{tabular}


Table 4. Wind speed data transformed into monthly frequency distribution format for Umm AlMaradim Island at 30m height for periods 1979-2015.

\begin{tabular}{lllllllllllll}
\hline & & & \multicolumn{1}{c}{ Wind Speed bins $(\mathrm{m} / \mathrm{s})$} \\
No/Sp & $0 .-1.0$ & $1 .-2.0$ & $2 .-3.0$ & $3 .-4.0$ & $4 .-5.0$ & $5 .-6.0$ & $6 .-7.0$ & $7 .-8.0$ & $8 .-9.0$ & $9 .-10$. & $>10$ \\
\hline Jan & 0.0363 & 0.0851 & 0.1223 & 0.1718 & 0.1783 & 0.1461 & 0.112 & 0.0741 & 0.0404 & 0.0184 & 0.0151 \\
Feb & 0.0278 & 0.0641 & 0.1147 & 0.1722 & 0.183 & 0.1499 & 0.1105 & 0.0783 & 0.0486 & 0.0286 & 0.0222 \\
Mar & 0.032 & 0.0697 & 0.1221 & 0.1756 & 0.1767 & 0.1454 & 0.1078 & 0.0761 & 0.0466 & 0.024 & 0.0241 \\
Apr & 0.028 & 0.0716 & 0.1291 & 0.1783 & 0.1875 & 0.1533 & 0.1071 & 0.0668 & 0.0416 & 0.0221 & 0.0148 \\
May & 0.0256 & 0.0744 & 0.1203 & 0.1862 & 0.1925 & 0.1522 & 0.1019 & 0.0703 & 0.0422 & 0.0197 & 0.0146 \\
Jun & 0.0249 & 0.0632 & 0.0999 & 0.13 & 0.1449 & 0.1391 & 0.1193 & 0.1043 & 0.0789 & 0.05 & 0.0456 \\
Jul & 0.0295 & 0.0609 & 0.1043 & 0.1418 & 0.1574 & 0.1447 & 0.1222 & 0.0979 & 0.066 & 0.0425 & 0.0328 \\
Aug & 0.0356 & 0.0865 & 0.1301 & 0.177 & 0.1765 & 0.1395 & 0.0964 & 0.0724 & 0.046 & 0.0255 & 0.0144 \\
Sep & 0.0409 & 0.1015 & 0.167 & 0.2073 & 0.1989 & 0.1134 & 0.0801 & 0.0458 & 0.026 & 0.0117 & 0.0074 \\
Oct & 0.0476 & 0.1011 & 0.1751 & 0.2292 & 0.1881 & 0.1133 & 0.0693 & 0.0393 & 0.0194 & 0.0089 & 0.0085 \\
Nov & 0.0427 & 0.0921 & 0.1358 & 0.1856 & 0.1834 & 0.1357 & 0.1011 & 0.0636 & 0.0316 & 0.0177 & 0.0106 \\
Dec & 0.0439 & 0.0886 & 0.1313 & 0.18 & 0.1782 & 0.1381 & 0.1031 & 0.0657 & 0.0357 & 0.0189 & 0.0165 \\
Year & 0.0346 & 0.0799 & 0.1293 & 0.1779 & 0.1788 & 0.1392 & 0.1026 & 0.0712 & 0.0436 & 0.024 & 0.0189 \\
Cumulative & 0.0346 & 0.1145 & 0.2438 & 0.4217 & 0.6005 & 0.7397 & 0.8423 & 0.9135 & 0.9571 & 0.9811 & 1 \\
\hline
\end{tabular}

Table 5. Monthly Weibull shape parameters $\mathrm{k}$ and scale parameters $\mathrm{c}$ for at Bubiyan, Failaka and Umm AlMaradim Islands for periods of 1979-2015.

\begin{tabular}{ccccccccccccccc}
\hline & Par & Jan & Feb & Mar & Apr & May & Jun & Jul & Aug & Sep & Oct & Nov & Dec & Year \\
\hline Bubiyan & $\mathrm{K}$ & 2.42 & 2.47 & 2.37 & 2.47 & 2.54 & 2.53 & 2.70 & 2.61 & 2.49 & 2.53 & 2.52 & 2.48 & 2.51 \\
Island & $\mathrm{C}$ & 3.96 & 4.28 & 4.23 & 4.14 & 4.15 & 4.80 & 4.65 & 4.11 & 3.63 & 3.47 & 3.78 & 3.86 & 4.09 \\
& $\mathrm{~K}$ & 2.46 & 2.53 & 2.42 & 2.46 & 2.52 & 2.52 & 2.70 & 2.63 & 2.44 & 2.54 & 2.57 & 2.55 & 2.53 \\
Failaka & $\mathrm{C}$ & 3.81 & 4.13 & 4.11 & 3.97 & 3.95 & 4.66 & 4.59 & 4.08 & 3.56 & 3.35 & 3.65 & 3.76 & 3.97 \\
Island & $\mathrm{C}$ & 2.50 & 2.51 & 2.38 & 2.49 & 2.53 & 2.53 & 2.68 & 2.58 & 2.47 & 2.55 & 2.54 & 2.53 & 2.52 \\
Umm & $\mathrm{K}$ & 2.50 & & & & & \\
AlMaradim & $\mathrm{C}$ & 4.92 & 5.16 & 5.04 & 4.88 & 4.88 & 5.75 & 5.54 & 4.90 & 4.36 & 4.18 & 4.69 & 4.83 & 4.93 \\
$\quad$ Island & $\mathrm{C}$ & & & & & & & & & & & & &
\end{tabular}

In order to observe the Weibull distribution of the three selected location, the Weibull probability density distributions for each of the 37 years were analyzed. The distributions obtained for the three locations are illustrated in figure 2 which represents Bubiyan island, Failaka Island and Umm AlMaradim Island respectively. It can be seen that the distributions for the three locations are similar for the 37 years period and represents a maximum peak at wind speed of about 4.0 $\mathrm{m} / \mathrm{s}$. The Rayleigh approximations of the actual probability density distribution of wind speeds for the period (1979-2015) for the three selected location are shown in the same figure. A comparison of the actual probability distribution of wind speeds derived from CIS database with Weibull and Rayleigh approximations for whole year presented in Table 6 for Bubiyan, Failaka and Umm AlMaradim islands respectively. It can be seen that the distributions for the three locations are similar for the 37 years period.

Table 6. Comparison of the actual (CIS data) probability distribution of wind speeds derived from data with Weibull and Rayleigh for periods 1979-2015.

\begin{tabular}{cccccccccccc}
\hline & & \multicolumn{4}{c}{ Bubiyan Island } & \multicolumn{3}{c}{ Failaka Island } & \multicolumn{3}{c}{ Umm AlMaradim Island } \\
$j$ & $v_{j}$ & $v_{m j}$ & CIS & Weibull & Rayleigh & CIS & Weibull & Rayleigh & CIS & Weibull & Rayleigh \\
\hline 1 & $0-1$ & 0.5 & 0.026 & 0.034 & 0.062 & 0.027 & 0.033 & 0.066 & 0.035 & 0.042 & 0.064 \\
2 & $1-2$ & 1.5 & 0.079 & 0.128 & 0.169 & 0.082 & 0.136 & 0.179 & 0.080 & 0.126 & 0.167 \\
3 & $2-3$ & 2.5 & 0.136 & 0.212 & 0.223 & 0.144 & 0.228 & 0.233 & 0.129 & 0.201 & 0.217 \\
4 & $3-4$ & 3.5 & 0.193 & 0.239 & 0.210 & 0.212 & 0.249 & 0.210 & 0.178 & 0.229 & 0.206 \\
5 & $4-5$ & 4.5 & 0.187 & 0.195 & 0.149 & 0.184 & 0.189 & 0.140 & 0.179 & 0.194 & 0.152
\end{tabular}




\begin{tabular}{lllllllllllll}
6 & $5-6$ & 5.5 & 0.139 & 0.117 & 0.081 & 0.135 & 0.103 & 0.070 & 0.139 & 0.122 & 0.087 \\
7 & $6-7$ & 6.5 & 0.098 & 0.052 & 0.034 & 0.092 & 0.043 & 0.029 & 0.103 & 0.058 & 0.039 & \\
8 & $7-8$ & 7.5 & 0.066 & 0.018 & 0.012 & 0.058 & 0.015 & 0.010 & 0.071 & 0.022 & 0.015 \\
9 & $8-9$ & 8.5 & 0.039 & 0.005 & 0.004 & 0.034 & 0.005 & 0.003 & 0.044 & 0.007 & 0.005 \\
10 & $9-10$ & 9.5 & 0.021 & 0.002 & 0.001 & 0.018 & 0.001 & 0.001 & 0.024 & 0.002 & 0.002 \\
11 & $>10$ & $>10$ & 0.017 & 0.001 & 0.001 & 0.015 & 0.001 & 0.001 & 0.019 & 0.001 & 0.001 \\
\hline
\end{tabular}
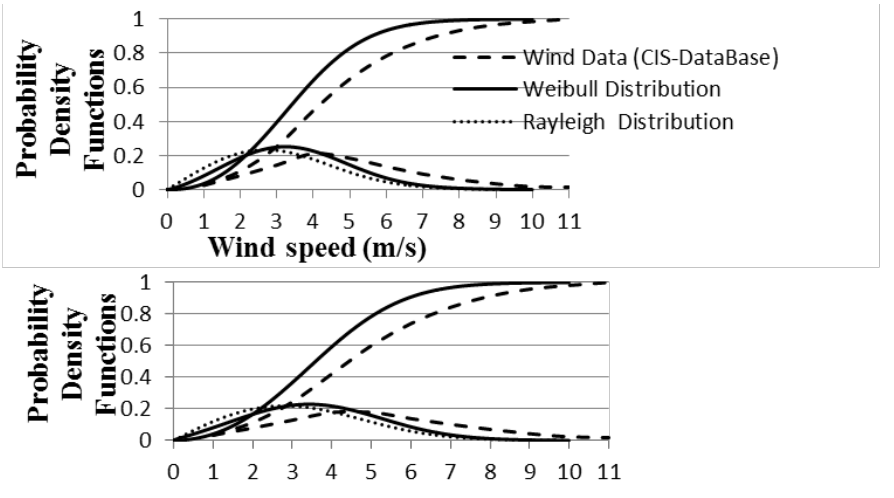

Wind speed $(\mathrm{m} / \mathrm{s})$

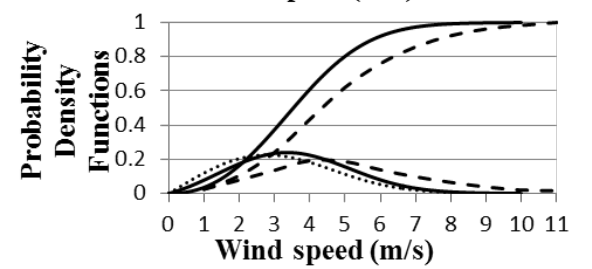

Figure 2. Wind speed probability density from Weibull and Reyleigh distribution and cumulative probability distributions for periods if 1979-2015 At Bubiyan, Failaka and Umm ALMaradim Islands respectively.

The parameters for the statistical analysis correlation coefficient $R^{2}$, the root mean square error, RMSE, and Chi-square error $X^{2}$, are given in Table 7 for the three selected locations. As it can be seen in Table 7 the value of correlation coefficient for Weibull is higher than the Rayleigh. The correlation coefficient values range from 0.6223 to 0.509 for the Weibull distribution, and Rayleigh distributions from 0.31 to 0.13 for the three selected location. However, the results have shown that the RMSE and $X^{2}$ values of the Weibull distribution are lower than the values obtained by the Rayleigh distribution for the three selected location. As result, the Weibull approximation is found to be the most accurate distribution according to the lower values of RMSE and higher $R^{2}$.

The frequency of wind power densities calculated from CIS database probability distributions are shown in figures 3, 4 and 5 and Tables 8, 9 and 10 for the three selected locations. The power density shows in percent of Frequency. The average power densities occur at each location as follows:

- For Bubiyan Island the highest yearly power density ranges of $150 \mathrm{w} / \mathrm{m}^{2}$ for frequency of occurrences about $36 \%$ and a cumulative WPD of $66 \%$.

- For Failaka Island the highest yearly power density range of 150 to $200 \mathrm{w} / \mathrm{m}^{2}$ for frequency of occurrences about $32 \%$ and cumulative WPD of $58 \%$.
- For Umm AlMaradim Island the highest yearly power density ranges of 150 to $200 \mathrm{w} / \mathrm{m}^{2}$ for frequency of occurrences about $29 \%$ and cumulative WPD of $55 \%$.

Design performance from a wind turbine, the wind speed at the three selected locations is the most important factor in how well a wind turbine performs for the amount of wind that's available. It's of little use installing a large turbine in an area which only receives a light breeze and likewise, it's a waste to install a smaller system on a site which could easily allow for greater power generation. The design performance should follow important factors as follows:

- A turbine's cut-in and cut-out speed are determined by the manufacturer to protect the turbine from damage. The cut-in speed is simple; it's the point at which the turbine starts generating electricity from turning. The cut-out point is more important, and denotes how fast the turbine can go before wind speeds get so fast that it risks damage.

- Rated peak speed - that is, a wind speed at which its return the optimal amount of power.

Figure 3, 4 and 5 are shows the design performance factors for a wind turbine at the three selected location. The cut-in speed which is at about $3 \mathrm{~m} / \mathrm{s}$ and the cut-out will be at about more the $10 \mathrm{~m} / \mathrm{s}$ and the peek speed for optimal of power generation 5-6 m/s at wind power 175 $w / m^{2}$. 
Table 7. The statistical analysis parameters for wind speed distributions for Period of 1979-2015.

\begin{tabular}{ccccccc}
\hline & \multicolumn{2}{c}{ Bubiyan Island } & \multicolumn{2}{c}{ Failaka Island } & \multicolumn{2}{c}{ Umm AlMaradim Island } \\
& Weibull & Rayleigh & Weibull & Rayleigh & Weibull & Rayleigh \\
\hline$R^{2}$ & 0.5936 & 0.2642 & 0.6223 & 0.3131 & 0.5099 & 0.1378 \\
$X^{2}$ & 0.0019 & 0.0034 & 0.0020 & 0.0036 & 0.0019 & 0.0033 \\
$R M S E$ & 0.0394 & 0.0530 & 0.0405 & 0.0546 & 0.0394 & 0.0522 \\
\hline
\end{tabular}

\section{CONCLUSIONS}

The objective of this study was to investigate the potential of wind energy resource in Mubarak Port area at Bubiyan island, Failaka Failaka Island and Umm AlMaradim Island in Kuwait. For this purpose, wind speed data obtained from the Costal Information System (CIS) database at the Kuwait institute for Scientific Research (KISR) were analyzed over a 37 years period from 1979 to 2015 . The probability density distributions and power density were derived from the time series data. Weibull and Rayleigh probability density function have been fitted to the wind speed and the wind power density was evaluated. The most important outcomes of the study can be summarized as follows:

- The predicted average annual peak wind power density for Bubiyan Island, Failaka
Island and a Umm AlMaradim Island are 150, 175 and $175 \mathrm{w} / \mathrm{m}^{2}$, respectively. These peak wind power is available for about $36 \%, 32 \%$ and $29 \%$ of the year for these locations.

- For Boubyan, Failaka and Umm Al-Maradim Islands, wind power exceeds $150 \mathrm{w} / \mathrm{m}^{2}$ for $33.6 \%, 42.3 \%$ and $56.5 \%$ in a year respectively

The Weibull distribution is better than the Rayleigh distribution for the monthly probability density distribution for the whole years. All the three sites fall under wind power class 2 (As per Pacific Northwest Laboratory (PNL) classification), since the wind power density values are more than $100 \mathrm{w} / \mathrm{m}^{2}$. Hence all these three sites are ideal for grid-connected applications.

Table 8. Frequency Distribution of Wind Power Density (\%) for Bubiyan Island (1979-2015).

Wind Power Density $\left(\mathrm{W} / \mathrm{m}^{\wedge} 2\right)$ Class

\begin{tabular}{lllllllllllll}
\hline No/Sp & 0 & 50 & 100 & 150 & 200 & 250 & 300 & 350 & 400 & 450 & 500 & 550 \\
\hline Jan & 0 & 0.0 & 37.8 & 51.4 & 10.8 & 0.0 & 0.0 & 0.0 & 0.0 & 0.0 & 0.0 & 0.0 \\
Feb & 0 & 0.0 & 8.1 & 56.8 & 24.3 & 8.1 & 0.0 & 0.0 & 2.7 & 0.0 & 0.0 & 0.0 \\
Mar & 0 & 0.0 & 5.4 & 51.4 & 35.1 & 8.1 & 0.0 & 0.0 & 0.0 & 0.0 & 0.0 & 0.0 \\
Apr & 0 & 2.7 & 18.9 & 54.1 & 16.2 & 8.1 & 0.0 & 0.0 & 0.0 & 0.0 & 0.0 & 0.0 \\
May & 0 & 0.0 & 27.0 & 45.9 & 16.2 & 8.1 & 2.7 & 0.0 & 0.0 & 0.0 & 0.0 & 0.0 \\
Jun & 0 & 0.0 & 2.7 & 10.8 & 43.2 & 10.8 & 8.1 & 13.5 & 2.7 & 5.4 & 2.7 & 0.0 \\
Jul & 0 & 0.0 & 2.7 & 29.7 & 24.3 & 21.6 & 5.4 & 2.7 & 8.1 & 5.4 & 0.0 & 0.0 \\
Aug & 0 & 0.0 & 24.3 & 40.5 & 13.5 & 16.2 & 0.0 & 0.0 & 2.7 & 2.7 & 0.0 & 0.0 \\
Sep & 0 & 10.8 & 35.1 & 35.1 & 16.2 & 2.7 & 0.0 & 0.0 & 0.0 & 0.0 & 0.0 & 0.0 \\
Oct & 0 & 18.9 & 59.5 & 10.8 & 5.4 & 2.7 & 0.0 & 0.0 & 2.7 & 0.0 & 0.0 & 0.0 \\
Nov & 0 & 5.4 & 54.1 & 16.2 & 13.5 & 10.8 & 0.0 & 0.0 & 0.0 & 0.0 & 0.0 & 0.0 \\
Dec & 0 & 2.7 & 51.4 & 27.0 & 5.4 & 8.1 & 5.4 & 0.0 & 0.0 & 0.0 & 0.0 & 0.0 \\
Year & 0 & 3.4 & 27.3 & 35.8 & 18.7 & 8.8 & 1.8 & 1.4 & 1.6 & 1.1 & 0.2 & 0.0 \\
Cumulative & 0 & 3.4 & 30.6 & 66.4 & 85.1 & 93.9 & 95.7 & 97.1 & 98.6 & 99.8 & 100.0 & 100 \\
\hline
\end{tabular}

Table 9. Frequency Distribution of Wind Power Density (\%) for Failaka Island (1979-2015).

Wind Power Density $\left(\mathrm{W} / \mathrm{m}^{\wedge} 2\right)$ Class

\begin{tabular}{|c|c|c|c|c|c|c|c|c|c|c|c|c|}
\hline $\mathrm{No} / \mathrm{Sp}$ & 0 & 50 & 100 & 150 & 200 & 250 & 300 & 350 & 400 & 450 & 500 & 550 \\
\hline Jan & 0 & 0.0 & 18.9 & 56.8 & 8.1 & 16.2 & 0.0 & 0.0 & 0.0 & 0.0 & 0.0 & 0.0 \\
\hline Feb & 0 & 0.0 & 5.4 & 45.9 & 27.0 & 16.2 & 2.7 & 0.0 & 2.7 & 0.0 & 0.0 & 0.0 \\
\hline Mar & 0 & 0.0 & 0.0 & 43.2 & 35.1 & 21.6 & 0.0 & 0.0 & 0.0 & 0.0 & 0.0 & 0.0 \\
\hline Apr & 0 & 2.7 & 16.2 & 32.4 & 40.5 & 5.4 & 2.7 & 0.0 & 0.0 & 0.0 & 0.0 & 0.0 \\
\hline May & 0 & 0.0 & 18.9 & 51.4 & 16.2 & 5.4 & 8.1 & 0.0 & 0.0 & 0.0 & 0.0 & 0.0 \\
\hline Jun & 0 & 0.0 & 0.0 & 10.8 & 37.8 & 21.6 & 0.0 & 16.2 & 2.7 & 2.7 & 5.4 & 2.7 \\
\hline
\end{tabular}




\begin{tabular}{lllllllllllll} 
Jul & 0 & 0.0 & 0.0 & 24.3 & 27.0 & 16.2 & 13.5 & 0.0 & 10.8 & 2.7 & 5.4 & 0.0 \\
Aug & 0 & 0.0 & 21.6 & 32.4 & 21.6 & 13.5 & 5.4 & 0.0 & 2.7 & 0.0 & 2.7 & 0.0 \\
Sep & 0 & 10.8 & 37.8 & 27.0 & 13.5 & 10.8 & 0.0 & 0.0 & 0.0 & 0.0 & 0.0 & 0.0 \\
Oct & 0 & 18.9 & 59.5 & 8.1 & 5.4 & 5.4 & 0.0 & 0.0 & 2.7 & 0.0 & 0.0 & 0.0 \\
Nov & 0 & 5.4 & 45.9 & 21.6 & 13.5 & 2.7 & 8.1 & 2.7 & 0.0 & 0.0 & 0.0 & 0.0 \\
Dec & 0 & 0.0 & 40.5 & 35.1 & 10.8 & 0.0 & 5.4 & 8.1 & 0.0 & 0.0 & 0.0 & 0.0 \\
Year & 0 & 3.2 & 22.1 & 32.4 & 21.4 & 11.3 & 3.8 & 2.3 & 1.8 & 0.5 & 1.1 & 0.2 \\
Cumulative & 0 & 3.2 & 25.2 & 57.7 & 79.1 & 90.3 & 94.1 & 96.4 & 98.2 & 98.6 & 99.8 & 100 \\
\hline
\end{tabular}

Table 10. Frequency Distribution of Wind Power Density (\%) for Umm AlMaradim Island (1979-2015). Wind Power Density $\left(\mathrm{W} / \mathrm{m}^{\wedge} 2\right)$ Class

\begin{tabular}{|c|c|c|c|c|c|c|c|c|c|c|c|c|}
\hline $\mathrm{No} / \mathrm{Sp}$ & 0 & 50 & 100 & 150 & 200 & 250 & 300 & 350 & 400 & 450 & 500 & 550 \\
\hline Jan & 0 & 0.0 & 8.1 & 43.2 & 21.6 & 10.8 & 10.8 & 5.4 & 0.0 & 0.0 & 0.0 & 0.0 \\
\hline Feb & 0 & 0.0 & 0.0 & 16.2 & 45.9 & 21.6 & 10.8 & 2.7 & 2.7 & 0.0 & 0.0 & 0.0 \\
\hline Mar & 0 & 0.0 & 0.0 & 21.6 & 43.2 & 27.0 & 8.1 & 0.0 & 0.0 & 0.0 & 0.0 & 0.0 \\
\hline Apr & 0 & 0.0 & 8.1 & 29.7 & 40.5 & 13.5 & 8.1 & 0.0 & 0.0 & 0.0 & 0.0 & 0.0 \\
\hline May & 0 & 0.0 & 10.8 & 35.1 & 32.4 & 10.8 & 10.8 & 0.0 & 0.0 & 0.0 & 0.0 & 0.0 \\
\hline Jun & 0 & 0.0 & 0.0 & 2.7 & 18.9 & 27.0 & 18.9 & 21.6 & 0.0 & 5.4 & 2.7 & 2.7 \\
\hline Jul & 0 & 0.0 & 2.7 & 10.8 & 29.7 & 16.2 & 18.9 & 5.4 & 10.8 & 2.7 & 2.7 & 0.0 \\
\hline Aug & 0 & 0.0 & 16.2 & 29.7 & 18.9 & 24.3 & 5.4 & 0.0 & 2.7 & 2.7 & 0.0 & 0.0 \\
\hline Sep & 0 & 0.0 & 35.1 & 43.2 & 13.5 & 8.1 & 0.0 & 0.0 & 0.0 & 0.0 & 0.0 & 0.0 \\
\hline Oct & 0 & 2.7 & 56.8 & 18.9 & 10.8 & 8.1 & 2.7 & 0.0 & 0.0 & 0.0 & 0.0 & 0.0 \\
\hline Nov & 0 & 0.0 & 27.0 & 37.8 & 10.8 & 8.1 & 8.1 & 2.7 & 0.0 & 5.4 & 0.0 & 0.0 \\
\hline Dec & 0 & 0.0 & 8.1 & 56.8 & 18.9 & 5.4 & 2.7 & 0.0 & 0.0 & 0.0 & 8.1 & 0.0 \\
\hline Year & 0 & 0.2 & 14.4 & 28.8 & 25.5 & 15.1 & 8.8 & 3.2 & 1.4 & 1.4 & 1.1 & 0.2 \\
\hline Cumulative & 0 & 0.2 & 14.6 & 43.5 & 68.9 & 84.0 & 92.8 & 95.9 & 97.3 & 98.6 & 99.8 & 100 \\
\hline
\end{tabular}

Figure 3. for wind power density (WPD) (W/m2) of Bubiyan Island.
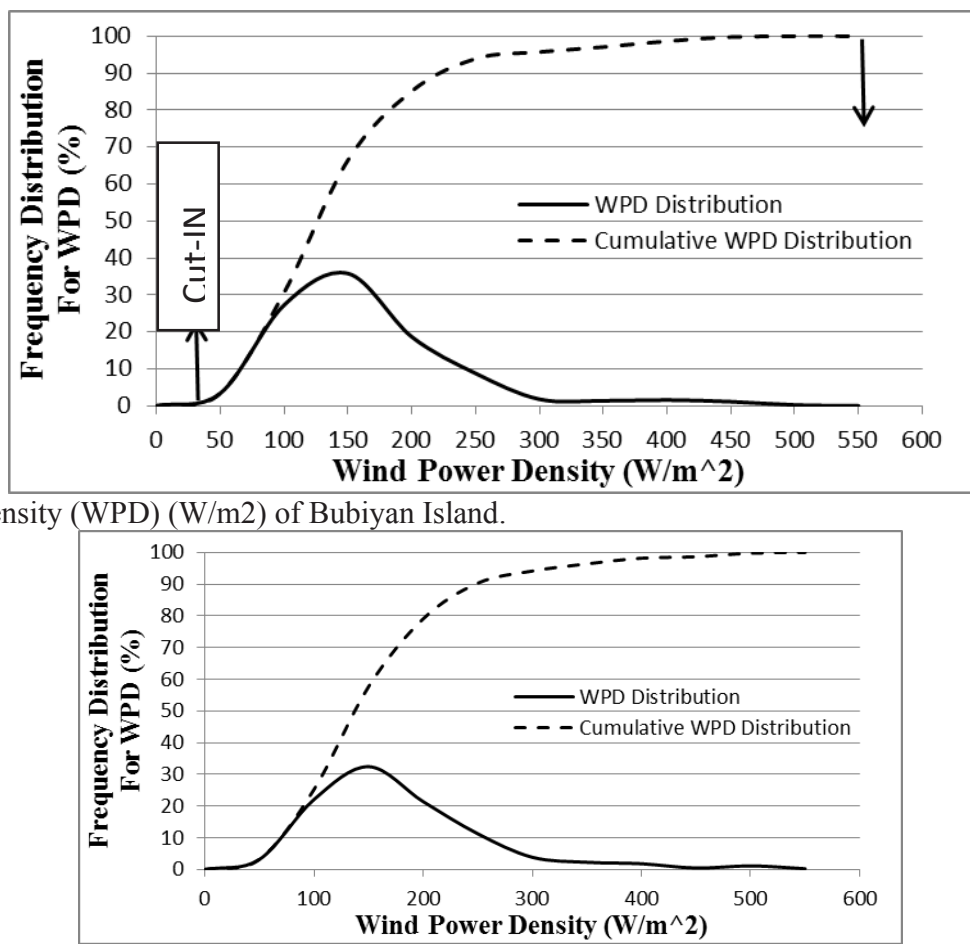

Figure 4. Distribution Wind power density $(\mathrm{W} / \mathrm{m} 2)$ of Failaka Island. 


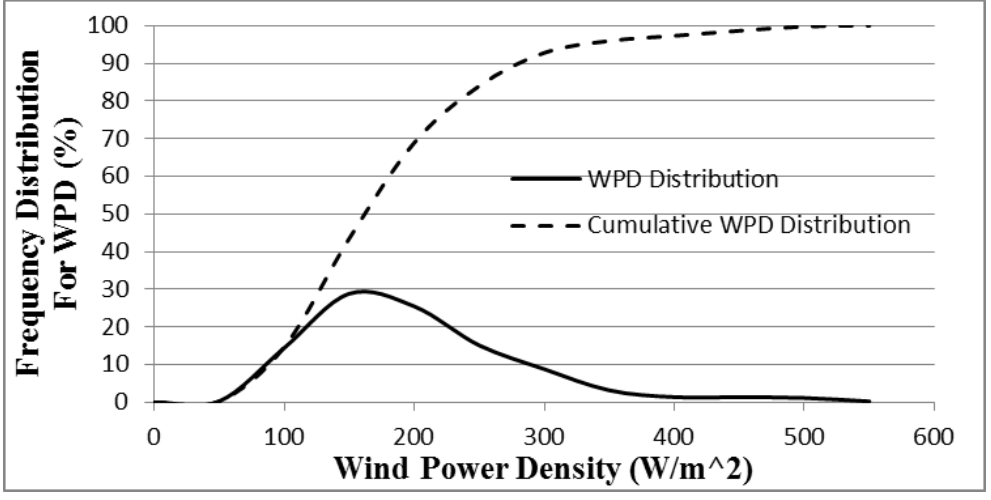

Figure 5. Distribution Wind power density (W/m2) of Umm AlMaradim Island.

\section{REFERENCE}

1. Al-Salem K. (2008), "Interactive Coastal Information System for Kuwait's Territorial

Waters Phase II: Website site for online Hydrodynamic Predictions". Kuwait Institute for Scientific Research. Report KISR 9485 Kuwait 2008.

2. Al-Salem K. and Al-Rashed A., 2016. "Updating the Database of KISR's Coastal Information System (CIS) by Using Numerical Techniques". Kuwait Institute for Scientific Research. Report KISR 13793. Kuwait 2016

3. Rakha K. and Al-Salem K., (2007) "Interactive Coastal Information System for Kuwait's Territorial Waters Phase I: Hindcast of wave, water levels and current". Kuwait Institute for Scientific Research (EC026C). Kuwait 2007.

4. Al-Naser, W. E.; Al-Naser, N. W. The Status of Renewable Energy in the GCC Countries. Renewable and Sustainable Energy Reviews. 2011, 15 (6), 3074-3098.

5. Al-Nassar. W.; Alhajraf S. A.; Al-Enizi, A.; AlAwadhi, L. Potential Wind Power Generation in the State of Kuwait. Renewable Energy. 2005, 30, 2149-2161.

6. Meishen Li, Xianguo Li. (2005). MEP-type distribution function: a better alternative to Weibull function for wind speed distributions. Renewable Energy; 30:1221-1240.

7. Egbert Boeker, Rienk Van Grondelle (1999). Environmental Physics. Second edition. John Wiley \& SONS, LTD.
8. Ramrez P, Carta JA. (2005). The use of wind probability distributions derived from the maximum entropy principle in the analysis of wind energy. A case study. Energy Conversion and Management; 1-14

9. Celik AN. (2003). A statistical analysis of wind power density based on the Weibull and Rayleigh models at the southern region of Turkey. Renewable Energy; 29:593-604.

10. Perez IA, Garcia MA, Sanchez ML, Torre de B. (2004). Analysis of height variations of sodarderived wind speeds in Northern Spain. Journal of Wind Engineering and Industrial Aerodynamics; 92:875-894.

11. Ahmed Shata AS, Hanitsch R. (2005). Evaluation of wind energy potential and electricity generation on the coast of editerranean Sea in Egypt. Renewable Energy; $1-20$.

12. Celik AN. (2004). On the distributional parameters used in assessment of the suitability of wind speed probability density functions. Energy Conversion and Management; 45: 1735-1747.

13. Al-Mohamad A, Karmeh. (2003): Wind energy potential in Syria. Renewable Energy ; 28: 10391046.

14. Al-Salem K., Rakha K. 2005."Verification of a WAM Model for the Arabian Gulf". Submitted to Arabian Coast 2005 Conference at Dubai 15 October 2005. 